\title{
An Inexact Credibility Chance-Constrained Integer Programming for Greenhouse Gas Mitigation Management in Regional Electric Power System under Uncertainty
}

\author{
W. $\mathrm{Li}^{1 *}$, Z. Bao ${ }^{1}$, G. H. Huang ${ }^{2}$, and Y. L. Xie \\ ${ }^{1}$ MOE Key Laboratory of Regional Energy Systems Optimization, S\&C Resources and Environmental Research Academy, North China Electric \\ Power University, Beijing 102206, China \\ ${ }^{2}$ Institute for Energy, Environment and Sustainability Research, UR-NCEPU, North China Electric Power University, Beijing 102206, China \\ ${ }^{3}$ School of Mechanical Engineering, University of Science and Technology Beijing, Beijing 100083, China
}

Received November 16, 2014; revised August 22, 2016; accepted August 31, 2016; published online January 12, 2018

\begin{abstract}
Electric power system (EPS) management considering greenhouse gas (GHG) mitigation is a challenging task, since many system parameters such as electric demand, resource availability, system cost as well as their interrelationships may appear uncertain. To reflect these uncertainties, in this study, an interval-parameter credibility constrained programming (ICCP) method was developed for electric power system planning in light of GHG mitigation. The method was advantageous in tackling uncertainties expressed as not only fuzzy possibilistic distributions associated with the right-hand-side components of model constraints but also discrete intervals in the objective function. In addition, ICCP allowed satisfaction of system constraints at specified confidence level, leading to model solutions with low system cost under acceptable risk magnitudes. The obtained results indicated that stable intervals for the objective function and decision variables could be generated, which were useful for helping decision makers identify the desired electric power generation patterns, capacity expansion schemes and GHG-emission reduction under complex uncertainties, and gain in-depth insights into the trade-offs between system economy and reliability.
\end{abstract}

Keywords: decision making, interval linear programming, credibility constrained programming, electric power system, uncertainty

\section{Introduction}

Effective planning of electric power system (EPS) plays an increasingly important role for electric utilities as well as human activities (Dentchva and Römisch, 1998; Huang and Chang, 2003; Cai et al., 2010; Li et al., 2010; Guo et al., 2012). For decades, rising electric demand, growing environmental/ health concerns, and shrinking resource availability have urged local authorities and regulatory agencies to seek comprehensive strategies for EPS planning. However, such planning efforts are often complicated with uncertainties associated with many economic, technical, environmental and political factors (Shimazaki et al., 2000; Cai et al., 2009; Bishop et al., 2010; Atkins et al., 2010; Siitonen et al., 2010; Cranston and Hammond, 2010; Xie et al., 2010; Xu et al., 2012; An et al., 2016; MartínFernández et al., 2016). For example, electric demand is uncertain since it depends on economic situations and user activities from residential, commercial, and industrial sectors; the operational cost of power generation facilities could fluctuate in a certain range (Cheng et al., 2002; Cao et al., 2010; Dong

\footnotetext{
* Corresponding author. Tel.: +8610 61772976; fax: +86 1061772978 .

E-mail address: weili1027@gmail.com(W.Li).
}

ISSN: 1726-2135 print/1684-8799 online

CC 2018 ISEIS All rights reserved. doi:10.3808/jei.201500326 et al., 2011). To reflect such uncertainties in EPS, inexact system-analysis techniques can be used (Gong et al., 2016; Lin et al., 2016; Tong et al., 2016). Examples are interval parameter programming (IPP) (Huang et al., 1992, 2011; GrosfeldNir and Tishler, 1993; Cai et al., 2008; Lin and Huang, 2008; Li et al., 2010, 2013), stochastic mathematical programming (SMP) (Grosfeld-Nir et al., 1993; Darby-Dowman et al., 2000; Li et al., 2009; Xie et al., 2010; Pousinho et al., 2011; Svensson et al., 2011; Qin, 2012; Wang et al., 2012) and fuzzy linear programming (FLP) (Huang et al., 1993; Huang et al., 1996; Yin et al., 1999; Chanas and Zielinski, 2000; Li et al., 2007; Muela et al., 2007; Lu et al., 2008).

Previously, many inexact optimization methods were proposed for energy system planning and management. For example, Lin and Huang (2008) developed an interval-parameter integer programming model for energy system planning, where the model used only the boundary information of parameters and had a low requirement on data quality (Xi et al., 2008). However, the major limitation of the interval-parameter model was that it did not allow any violation of the system constraints and the model became infeasible when the right-hand side parameters in the constraints were highly uncertain (Huang et al., 1993). In order to solve this problem, Liu et al. (2000) introduced a hybrid inexact chance-constrained mixed-integer linear programming method for nonrenewable energy resources management. The method optimally allocated limited nonre- 
newable energy resources over different time periods for acquiring the maximized benefit under uncertainty. Cai et al. (2009) proposed an inexact community-scale energy model, which incorporated interval linear programming (ILP) and chance-constrained programming (CCP) within a general optimization framework. The model results offered cost-effective energy resource/service allocation and capacity-expansion plans with proper balances among system cost, system reliability and energy security. Liu et al. (2009) formulated an inexact management model to systematically handle complexities in integrated coal and power management systems, where the model led to a series of solutions with optimal system cost/ benefit at allowable levels of violation risks.

However, in many real-world management problems, it is widely recognized that the right-hand side model constraints would encounter fuzzy uncertainties (Huang, 2006). The chanceconstrained programming with fuzzy parameters (FCCP) is proposed to deal with such a problem, where a number of predefined confidence levels of fuzzy-constraints-satisfaction will be incorporated into the optimization model. Previously, FCCP has been successfully used in many applications. Huang (2006) discussed a problem involving capital budgeting in a fuzzy environment, and two types of fuzzy possibility chanceconstrained programming models were provided. Rong and Lahdelma (2008) presented the fuzzy credibility chance constrained model for scrap charge optimization. However, applications of FCCP in EPS planning field were limited, due to the fact that FCCP may encounter difficulties in obtaining fuzzy distribution information due to lack of data or difficulties in obtaining the data which are common issues for large-scale EPS planning systems. Representation of uncertain information using multiple theories would be more desirable (Zhang and Huang, 2011).

Therefore, the objective of this study is to develop an interval-parameter credibility constrained programming (ICCP) method for regional EPS management under considering GHGemission reduction. It is an attempt to develop a risk control method for renewable energy utilization and GHG mitigation. The developed model is a hybrid of interval-parameter linear programming and credibility constrained programming. Uncertainties are expressed as not only possibility distributions associated with right-hand-side components of constraints but also discrete intervals in the objective function. Moreover, ICCP allows violation of system constraints at specified confidence levels, leading to solutions with low system costs under acceptable magnitudes of violation risks.

\section{Methodology}

\subsection{Interval Linear Programming}

Interval linear programming (ILP) where coefficients of the decision variables in the objective function and constraints are presented as interval values can be formulated as follows:

Maximize $f^{ \pm}=C^{ \pm} X^{ \pm}$

Subject to:
$A^{ \pm} X^{ \pm} \leq B^{ \pm}$

$X^{ \pm} \geq 0$

where $X^{ \pm} \in\left\{\Re^{ \pm}\right\}^{n \times l}, A^{ \pm} \in\left\{\Re^{ \pm}\right\}^{m \times n}, B^{ \pm} \in\left\{\mathfrak{R}^{ \pm}\right\}^{m \times l}, C^{ \pm} \in\left\{\mathfrak{R}^{ \pm}\right\}^{l \times n}$, $\mathfrak{R}^{ \pm}$denotes a set of interval numbers. The ILP model can be transformed into two deterministic sub-models, i.e., $f^{+}$and $f^{-}$, which correspond to the lower and upper bounds of the objecttive function values. By solving the submodels, the relevant solutions can be obtained as follows: $x_{j \text { opt }}=\left[x_{j \text { opt }}^{-}, x_{j \text { opt }}^{+}\right], f_{\text {opt }}$ $=\left[f_{\text {opt }}^{-}, f_{\text {opt }}^{+}\right]$.

\subsection{Credibility Constrained Programming}

Credibility constrained programming (CCP), which based on credibility conception, can be expressed as follows (Huang, 2006; Rong and Lahdelma, 2008):

Maximize $\sum_{j=1}^{n} c_{j} X_{j}$

Subject to:

$$
\begin{aligned}
& \operatorname{Cr}\left\{\sum_{j=1}^{n} a_{i j} x_{j} \leq \tilde{b}_{i}, i=1,2, \ldots, \mathrm{m}\right\} \geq \lambda_{i} \\
& x_{j} \geq 0, i=1, \ldots, n
\end{aligned}
$$

where $x=\left(x_{1}, x_{2}, \ldots, x_{n}\right)$ is a vector of non-fuzzy decision variables; $c_{j}$ are cost coefficients; $a_{i j}$ are technical coefficients; $\tilde{b}_{i}$ are right-hand side coefficients; $\operatorname{Cr}\{\bullet\}$ denotes the credibility of the event $\{\bullet\} ; \lambda$ is the confidence level.

Let $\xi$ be a fuzzy variable with membership function $\mu$, and let $u$ and $r$ be real numbers. Dubois and Prade (1988) proposed the following indices defined by possibility and necessity measures:

$$
\begin{aligned}
& \operatorname{Pos}\{\xi \leq r\}=\sup _{u \leq r} \mu(u) \\
& \operatorname{Nec}\{\xi \leq r\}=1-\operatorname{Pos}\{\xi>r\}=1-\sup _{u>r} \mu(u)
\end{aligned}
$$

The credibility measure $\mathrm{Cr}$ is the average of the possibility measure and the necessity measure (Liu and Liu, 2002):

$$
\operatorname{Cr}\{\xi \leq r\}=\frac{1}{2}(\operatorname{Pos}\{\xi \leq r\}+\operatorname{Nec}\{\xi \leq r\})
$$

Let the fuzzy variable $\xi$ be fully determined by the triplet $(\underline{t}, t, \bar{t})$ of crisp numbers with $\underline{t}<t<\bar{t}$, whose membership function is given by:

$\mu(r)= \begin{cases}(r-\underline{t}) /(t-\underline{t}) & \text { if } \underline{t} \leq r \leq t, \\ (\bar{t}-r) /(\bar{t}-t) & \text { if } t \leq r \leq \bar{t}, \\ 0 & \text { otherwise. }\end{cases}$ 
From the above definitions, the possibility, necessity, and credibility of $r \leq \xi$ are provided as follows:

$$
\begin{aligned}
& \operatorname{Pos}\{\xi \leq r\}= \begin{cases}0 & \text { if } r \leq \underline{t} \\
\frac{r-\underline{t}}{t-\underline{t}} & \text { if } \underline{t} \leq r \leq t \\
1 & \text { if } r \geq t\end{cases} \\
& \operatorname{Nec}\{\xi \leq r\}= \begin{cases}0 & \text { if } r \leq t \\
\frac{r-t}{\bar{t}-t} & \text { if } t \leq r \leq \bar{t} \\
1 & \text { if } r \geq \bar{t}\end{cases} \\
& \operatorname{Cr}(r \leq \xi)= \begin{cases}0 & \text { if } r \leq \underline{t} \\
\frac{r-\bar{t}}{2(t-\bar{t})} & \text { if } \underline{t}<r \leq t \\
\frac{2 t-\underline{t}-r}{2(t-\underline{t})} & \text { if } t \leq r<\bar{t} \\
1 & \text { if } r \geq \bar{t}\end{cases}
\end{aligned}
$$

Let $\sum_{j=1}^{n} a_{i j} x_{j}$ be replaced by Si. Thus, the constraint (2b) can be represented as:

$\operatorname{Cr}\left\{s_{i} \leq \tilde{b}_{i}, i=1, \ldots, m\right\} \geq \lambda_{i}, \sqrt{b^{2}-4 a c}$

Normally, a significant credibility level should be greater than 0.5 . Therefore, based on the definition of credibility, we have the following equation for each $1 \geq \mu_{t_{i}} \geq \lambda_{i} \geq 0.5$ :

$\frac{2 b_{i}-\underline{b}_{i}-s_{i}}{2\left(b_{i}-\underline{b}_{i}\right)} \geq \lambda_{i}$

where $\tilde{b}_{i}$ are right-hand side coefficients fully determined by the triplet $\left(\underline{b}_{i}, b_{i}, \bar{b}_{i}\right)$ of crisp numbers with $\underline{b}_{i}<b_{i}<\bar{b}_{i}$, whose membership function is $\mu$.

\subsection{Interval-parameter Credibility Constrained Programming}

To tackle multi-type uncertainties, the ILP and CCP methods can be incorporated within a general optimization framework. Then an interval-parameter credibility constrained programming (ICCP) model can be formulated as follows:

$\operatorname{Maximize} \sum_{j=1}^{n} c_{j}^{ \pm} x_{j}^{ \pm}$

Subject to:

$\operatorname{Cr}\left\{\sum_{j=1}^{n} a_{i j}^{ \pm} x_{j}^{ \pm} \leq \tilde{b}_{i}, i=1, \ldots, m\right\} \geq \lambda_{i}^{ \pm}$, $x_{j}^{ \pm} \geq 0, j=1, \ldots, n$

Let $\sum_{j=1}^{n} a_{i j}^{ \pm} x_{j}^{ \pm}=s_{i}^{ \pm} \quad$ be the credibility constraints. The interval credibility levels, parameters and variables for such constraints can be formulated as:

$\operatorname{Cr}\left\{s_{i}^{ \pm} \leq \tilde{b}_{i}, i=1, \ldots, m\right\} \geq \lambda_{i}^{ \pm}$.

Therefore, based on the definition of credibility, we have the following expression for each $1 \geq \mu_{\tilde{t}_{i}} \geq \lambda_{i} \geq 0.5$ :

$$
\frac{2 b_{i}-\underline{b}_{i}-s_{i}^{ \pm}}{2\left(b_{i}-\underline{b}_{i}\right)} \geq \lambda_{i}^{ \pm}
$$

Thus, the ICCP can be transformed to an equivalent model as follows:

$\operatorname{Maximize} \sum_{j=1}^{n} c_{j}^{ \pm} x_{j}^{ \pm}$

Subject to:

$\sum_{j=1}^{n} a_{i j}^{ \pm} x_{j}^{ \pm} \leq b_{i}+\left(1-2 \lambda_{i}^{ \pm}\right)\left(b_{i}-\underline{b}_{i}\right)$

$x_{j}^{ \pm} \geq 0, \forall j$

\subsection{Solution Method}

The developed model can be transformed into two deterministic sub-models, corresponding to the lower and upper bounds of the preferred objective function value. When the objective function is to maximize $f^{ \pm}$, the sub-model corresponding to $f^{+}$should be solved first. The ICCP sub-model corresponding to the upper bound of the objective-function value is:

$\operatorname{Maximize} f^{+}=\sum_{j=1}^{k_{1}} c_{j}^{+} x_{j}^{+}+\sum_{j=k_{1}+1}^{n} c_{j}^{+} x_{j}^{-}$

Subject to:

$\sum_{j=1}^{k_{1}}\left|a_{i j}^{ \pm}\right|^{-} \operatorname{sign}\left(a_{i j}^{ \pm}\right) x_{j}^{+}+\sum_{j=k_{1}+1}^{n}\left|a_{i j}^{ \pm}\right|^{+} \operatorname{sign}\left(a_{i j}^{ \pm}\right) x_{j}^{-} \leq b_{i}+\left(1-2 \lambda_{i}^{-}\right)\left(b_{i}-\underline{b}_{i}\right)$

where $x_{j}^{+}$are upper bounds of interval variables with positive coefficients in the objective function, and $x_{j}^{-}$are lower bounds of interval variables with negative coefficients. By solving the sub-model $f^{+}$, the upper limits of the solutions can be obtained.

Similarly, the sub-model corresponding to $f^{-}$can be formulated as follows: 
Maximize $f^{-}=\sum_{j=1}^{k_{1}} c_{j}^{-} x_{j}^{-}+\sum_{j=k_{1}+1}^{n} c_{j}^{-} x_{j}^{+}$

Subject to:

$$
\sum_{j=1}^{k_{1}}\left|a_{i j}^{ \pm}\right|^{+} \operatorname{sign}\left(a_{i j}^{ \pm}\right) x_{j}^{-}+\sum_{j=k_{1}+1}^{n}\left|a_{i j}^{ \pm}\right|^{-} \operatorname{sign}\left(a_{i j}^{ \pm}\right) x_{j}^{+} \leq b_{i}+\left(1-2 \lambda_{i}^{+}\right)\left(b_{i}-\underline{b}_{i}\right)
$$

By solving the sub-model $f^{-}$, the lower limits of the solutions can be obtained. Thus the optimal solution of ICCP model can be obtained as: $f_{o p t}^{ \pm}=\left[f_{o p t}^{-}, f_{o p t}^{+}\right], x_{o p t}^{ \pm}=\left[x_{o p t}^{-}, x_{o p t}^{+}\right]$.

\section{Case Study}

\subsection{Overview of the Study System}

A hypothetical regional EPS planning problem is studied to illustrate the applicability of the proposed ICCP approach. The problem under consideration is how to effectively allocate the five types (including imported electricity) of electricity supplies and generate expansion plans to meet the increasing end-use demand and environmental limitations over the planning horizon with a minimum cost. Three periods (5-year for each period) are considered in the planning horizon. There are four types of energy resources for electricity generation in a regional power system, including coal, natural gas, hydropower, and wind power, respectively. Cor- respondingly, four kinds of conversion technologies are available, the initial installed capacities of coal-fired power, na tural gas-fired power, hydropower and wind power conversion technologies are $1.5,0.35,0.25$, and $0.05 \mathrm{GW}$, respectively. Figure 1 shows interactive relationships of differrent components within the regional-scale electric power system. The power system contains three parts: the energy supply for power generation, the conversion of power generation, and the allocation of power. The available amounts of renewable energy resources are affected by local natural conditions, such as precipitation and wind variations; meanwhile, the electric demand is dependent on economic situations and user activities. Generally, these parameters are estimated empirically. In order to reflect ambiguity and vagueness in resource availabilities and electric demand, they are presented as fuzzy numbers (as shown in Table 1). Other parameters, such as supply cost and expansion amounts, fluctuate in a small range and they are described by interval numbers. For example, over three periods, the supply costs of coal are [2.5, 4.0], [3.5, 5.0], and [4.5, 6.0] \$million/PJ, respectively; those of natural gas are $[5.0,7.0],[6.0,8.0]$ and $[7.0,9.0]$ $\$$ million/PJ respectively; those of imported electricity are $[15.0,20.0],[17.0,22.0]$ and $[19.0,24.0]$ \$million/PJ, respectively. It is assumed that there is no supply cost for the renewable energy resources (hydropower and wind power). During each period, there are three expansion options for each power conversion technology and they have different expansion amounts. The expansion cost of conversion technology is divided into two types, including the investment cost (i.e.,

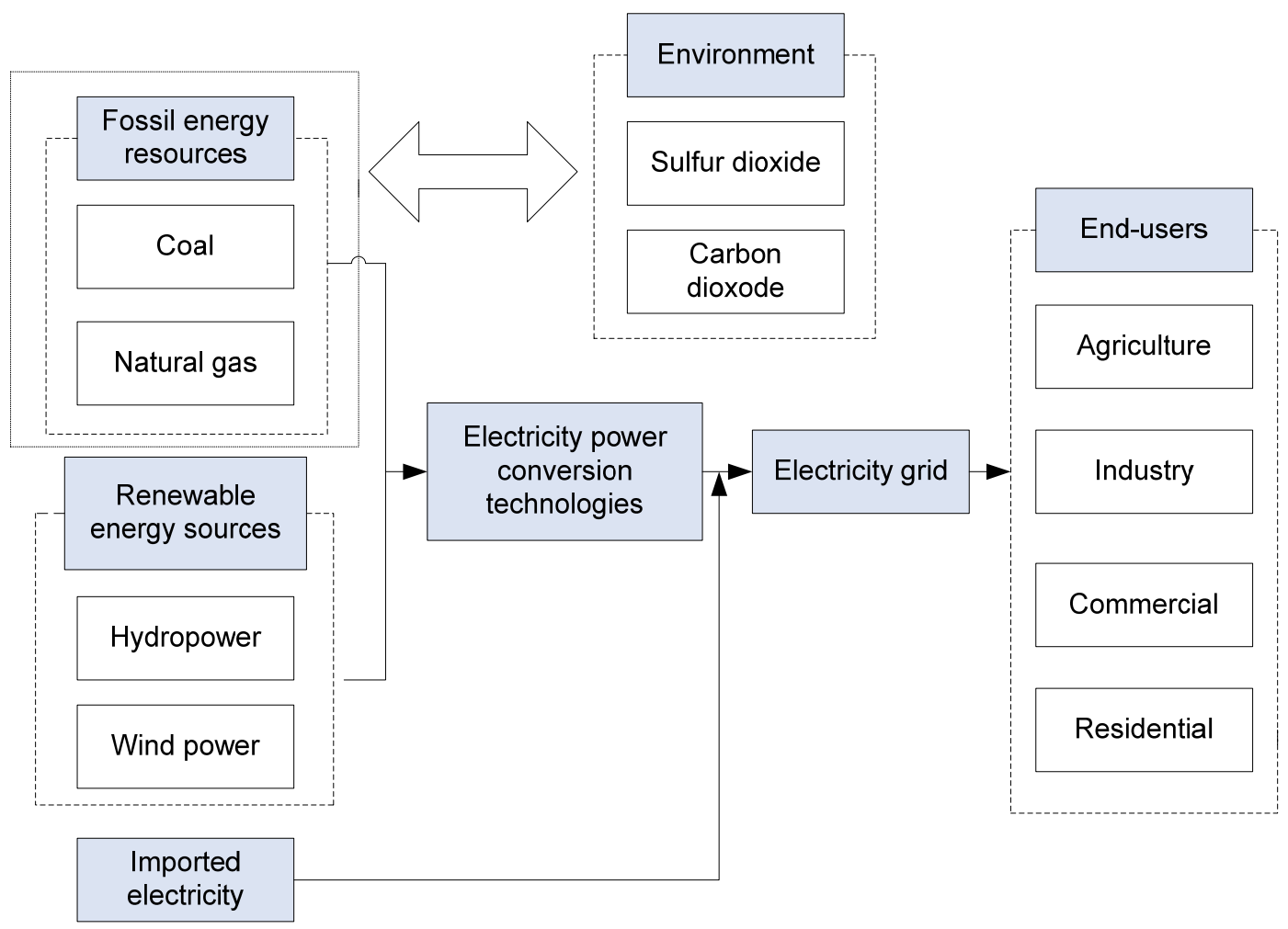

Figure 1. Interactive relationships within regional-scale electric power system. 
Table 1. Electric Demand and Renewable Energy Availability in Three Periods

\begin{tabular}{llll}
\hline & $\mathrm{t}=1$ & $\mathrm{t}=2$ & $\mathrm{t}=3$ \\
\hline Electricity demand $(\mathrm{PJ})$ & {$[1950,2200,2450]^{*}$} & {$[2100,2350,2600]$} & {$[2250,2500,2750]$} \\
Availabilities of renewable energy $(\mathrm{GW})$ & & & \\
Hydropower $(\mathrm{k}=3)$ & {$[0.65,0.70,0.75]$} & {$[1.15,1.20,1.25]$} & {$[1.60,1.65,1.70]$} \\
Wind power $(\mathrm{k}=4)$ & {$[0.35,0.40,0.45]$} & {$[0.75,0.80,0.85]$} & {$[1.15,1.20,1.25]$} \\
\hline
\end{tabular}

* $[\mathrm{a}, \mathrm{b}, \mathrm{c}]$ denotes the triangular fuzzy set, where $\mathrm{a}$ and $\mathrm{c}$ are the minimum and maximum possible values and $\mathrm{b}$ is the most likely value.

Table 2. Fixed-charge Expansion Cost and Expansion Options for Power-Generation Facilities

\begin{tabular}{|c|c|c|c|c|}
\hline \multirow{2}{*}{ Conversion technology } & \multirow{2}{*}{ Expansion capacity (MW) } & \multicolumn{3}{|c|}{ Fixed-charge expansion cost (million dollar) } \\
\hline & & $\mathrm{t}=1$ & $\mathrm{t}=2$ & $\mathrm{t}=3$ \\
\hline \multicolumn{5}{|l|}{ Coal-fired $(\mathrm{k}=1)$} \\
\hline Option $1(\mathrm{~m}=1)$ & 100 & {$[230,241]$} & {$[235,246]$} & {$[240,250]$} \\
\hline Option $2(\mathrm{~m}=2)$ & 200 & {$[260,271]$} & {$[265,276]$} & {$[270,280]$} \\
\hline Option $3(\mathrm{~m}=3)$ & 300 & {$[290,302]$} & {$[295,306]$} & {$[300,310]$} \\
\hline \multicolumn{5}{|l|}{ Natural gas-fired $(\mathrm{k}=2)$} \\
\hline Option $1(\mathrm{~m}=1)$ & 400 & {$[320,334]$} & {$[325,340]$} & {$[330,345]$} \\
\hline Option $2(\mathrm{~m}=2)$ & 500 & {$[355,370]$} & {$[360,375]$} & {$[365,380]$} \\
\hline Option $3(\mathrm{~m}=3)$ & 600 & {$[390,406]$} & {$[395,410]$} & {$[400,415]$} \\
\hline \multicolumn{5}{|l|}{ Hydropower $(\mathrm{k}=3)$} \\
\hline Option $1(\mathrm{~m}=1)$ & 300 & {$[515,527]$} & {$[520,530]$} & {$[525,535]$} \\
\hline Option $2(\mathrm{~m}=2)$ & 400 & {$[570,582]$} & {$[575,585]$} & {$[580,590]$} \\
\hline Option $3(\mathrm{~m}=3)$ & 500 & {$[625,637]$} & {$[630,640]$} & {$[635,645]$} \\
\hline \multicolumn{5}{|l|}{ Wind power $(\mathrm{k}=4)$} \\
\hline Option $1(\mathrm{~m}=1)$ & 200 & {$[520,532]$} & {$[525,535]$} & {$[530,538]$} \\
\hline Option $2(\mathrm{~m}=2)$ & 300 & {$[580,593]$} & {$[585,595]$} & {$[590,598]$} \\
\hline Option $3(\mathrm{~m}=3)$ & 400 & {$[640,653]$} & {$[645,655]$} & {$[650,658]$} \\
\hline
\end{tabular}

fixed cost) and the operating cost (i.e., variable cost), respectively. The related parameters are shown in Tables 2 and 3.

To tackle the above-mentioned problem, the proposed ICCP will be applied. The best way to reflect decision maker's preferences is to express them through linguistic terms and establishing a semantic correspondence at different levels of feasibility (Zadeh, 1978; Mariano et al., 2007). Linguistic terms are encountered in data acquisition, when subjective judgment is involved. In this study, 11 semantic scales are used to represent the credibility levels of decision makers. The corresponding linguistic terms and credibility levels of the constraints are tabulated in Table 4. By setting the acceptable semantic terms of decision makers, acceptable interval credibility levels can then be generated.

\subsection{ICCP Model for Regional Power Electric System Planning}

The objective of the proposed model is to obtain a preferred plan for various energy activities by minimizing the total cost, which is related to energy resource supply, energy conversion, capacity expansion and environmental protection. The model constraints involve mass balance, emission, and technical restrictions. The regional power electric system planning problem can then be formulated as follows:
Table 3. Variable Expansion Cost for Power-generation Facilities

\begin{tabular}{llll}
\hline \multirow{2}{*}{ Conversion technology } & \multicolumn{3}{l}{ Variable expansion cost $($ \$million $/ \mathrm{GW})$} \\
\cline { 2 - 4 } & $\mathrm{t}=1$ & $\mathrm{t}=2$ & $\mathrm{t}=3$ \\
\hline Coal-fired $(\mathrm{k}=1)$ & {$[255,265]$} & {$[260,275]$} & {$[270,285]$} \\
Natural gas-fired $(\mathrm{k}=2)$ & {$[320,335]$} & {$[330,345]$} & {$[340,355]$} \\
Hydropower $(\mathrm{k}=3)$ & {$[500,515]$} & {$[510,525]$} & {$[520,535]$} \\
Wind power $(\mathrm{k}=4)$ & {$[550,565]$} & {$[560,575]$} & {$[570,585]$} \\
\hline
\end{tabular}

Table 4. 11 Scales of Linguistic Terms

\begin{tabular}{ll}
\hline$\lambda$ & Term \\
\hline 0 & Unsatisfied constraint \\
0.1 & Practically unsatisfied constraint \\
0.2 & Almost unsatisfied constraint \\
0.3 & Very unsatisfied constraint \\
0.4 & Quite unsatisfied constraint \\
0.5 & Neither satisfied nor unsatisfied constraint \\
0.6 & Quite satisfied constraint \\
0.7 & Very satisfied constraint \\
0.8 & Almost satisfied constraint \\
0.9 & Practically satisfied constraint \\
1 & Completely satisfied constraint \\
\hline
\end{tabular}




$$
\begin{aligned}
\text { Minimize } f^{ \pm}= & \sum_{j=1}^{3} \sum_{t=1}^{3}\left(P T C_{j t}^{ \pm} \cdot Z_{j t}^{ \pm} \cdot \beta\right)+\sum_{k=1}^{4} \sum_{t=1}^{3}\left(P V_{k t}^{ \pm} \cdot X_{k t}^{ \pm} \cdot \beta\right) \\
& +\sum_{k=1}^{4} \sum_{m=1}^{3} \sum_{t=1}^{3} Y_{k m t}^{ \pm} \cdot\left(F C_{k m t}^{ \pm}+V C_{k t}^{ \pm} \cdot E C P_{k m t} \cdot \beta\right) \\
& +\sum_{k=1}^{4} \sum_{t=1}^{3} \sum_{r=1}^{2}\left(X_{k t}^{ \pm} \cdot C O T_{k t}^{ \pm} \cdot C T_{k t}^{ \pm} \cdot \beta\right)
\end{aligned}
$$

Subject to:

Constraint for coal balance:

$C F_{1 t} \cdot\left[R C_{1}+\sum_{m=1}^{3} \sum_{t^{\prime}=1}^{t} Y_{1 m t}^{ \pm} \cdot E C P_{1 m t}\right] \cdot F E_{1 t}^{ \pm} \leq Z_{1 t}^{ \pm}, \forall t$

Constraint for natural gas balance:

$C F_{2 t} \cdot\left[R C_{2}+\sum_{m=1}^{3} \sum_{t^{\prime}=1}^{t} Y_{2 m t}^{ \pm} \cdot E C P_{2 m t}\right] \cdot F E_{2 t}^{ \pm} \leq Z_{2 t}^{ \pm}, \forall t$

Constraint for hydropower:

$C F_{3 t} \cdot\left[R C_{3}+\sum_{m=1}^{3} \sum_{t^{\prime}=1}^{t} Y_{3 m t}^{ \pm} \cdot E C P_{3 m t}\right] \cdot F E_{3 t}^{ \pm} \leq X_{3 t}^{ \pm}, \forall t$

Constraint for wind power:

$C F_{4 t} \cdot\left[R C_{4}+\sum_{m=1}^{3} \sum_{t^{\prime}=1}^{t} Y_{4 m t}^{ \pm} \cdot E C P_{4 m t}\right] \cdot F E_{4 t}^{ \pm} \leq X_{4 t}^{ \pm}, \forall t$

Constraint for electricity demand:

$\operatorname{Cr}\left\{\sum_{k=1}^{4} X_{k t}^{ \pm}+Z_{3 t}^{ \pm} \geq \tilde{D}_{t}\right\} \geq \lambda^{ \pm}, \forall t$

Constraint for renewable energy resource availabilities:

$\operatorname{Cr}\left\{R C_{k}+\sum_{m=1}^{3} \sum_{t^{\prime}=1}^{t} Y_{k m t}^{ \pm} \cdot E C P_{k m t} \leq \tilde{V}_{k t}\right\} \geq \lambda^{ \pm}, \forall t, k=3,4$

Constraint for environmental protection:

$\sum_{k=1}^{4} X_{k t}^{ \pm} \cdot \operatorname{COT}_{k t}^{ \pm} \cdot\left(1-\eta_{k t}^{ \pm}\right) \leq E S_{t}^{ \pm}, \forall t$

$\sum_{k=1}^{4} X_{k t}^{ \pm} \cdot C O P_{k t}^{ \pm} \leq E P_{t}^{ \pm}, \forall t$

Constraint for capacity expansion:

$Y_{k m t}^{ \pm}\left\{\begin{array}{ll}=1 & \text { if capacity expansion is undertaken } \\ =0 & \text { otherwise }\end{array}, \forall k, m, t\right.$

$\sum_{m=1}^{3} Y_{k m t}^{ \pm} \leq 1, \forall k, t$

Constraint for technical and non-negative:

$Z_{j t}^{ \pm} \geq 0, \forall j, t$

$X_{k t}^{ \pm} \geq 0, \forall k, t$

where $f^{ \pm}$is the expected system cost over the planning periods (million dollar); $j$ is the index of energy resource, with $j$
$=1$ for coal, $j=2$ for natural gas, and $j=3$ for imported electricity; $t$ is the planning period, $t=1,2,3 ; k$ is the type of power conversion technology, representing coal power generation technology $(k=1)$, natural gas power generation technology $(k=2)$, hydropower $(k=3)$, and wind power $(k=4)$, respectively; $m$ is the expansion option, $m=1,2,3 ; \beta$ is a single period discount factor, $\beta=1 /(1+i)^{t}=[P / F, i, t]$; and $i$ is the interest rate per period (i.e. period $t$ ); $P T C_{i t}^{ \pm}$is the supply cost of energy resources $i$ in period $t$ (\$million/PJ); $P V_{k t}^{ \pm}$is the conversion cost for electricity generated by technology $k$ in period $t$ (\$million/PJ); $F C_{k m t}^{ \pm}$is the fixedcharge expansion cost for conversion technology $k$ with option $m$ during period $t$ (\$million/GW); $V C_{k t}^{ \pm}$is the variable expansion cost for conversion technology $k$ with option $m$ during period $t(\$$ million$/ \mathrm{GW}) ; E C P_{k m t}$ is the capacity expansion amount for conversion technology $k$ with option $m$ during period $t(\mathrm{GW})$. $C O T_{k t}^{ \pm}$is the emission intensity of sulfur dioxide from power generation technology $k$ in period $t$ (kiloton/PJ); $C O P_{k t}^{ \pm}$is the emission intensity of carbon dioxide from power generation technology $k$ in period $t$ (kiloton/PJ). $C T_{k t}^{ \pm}$is the removal cost of sulfur dioxide from power generation technology $k$ in period $t$ (\$million/kiloton); $C F_{k t}$ is conversion coefficient for power generation to energy resource from conversion technology $k$ in period $t(\mathrm{PJ} /$ $\mathrm{GW}) ; \tilde{D}_{t}$ is electricity demand during period $t(\mathrm{PJ}) ; R C_{k}$ is residual capacity of power generation technology $k(\mathrm{GW})$; $F E_{k t}^{ \pm}$is conversion coefficient for power generation capacity to electricity generation from conversion technology $k$ in pe$\operatorname{riod} t(\mathrm{PJ} / \mathrm{PJ}) ; \tilde{V}_{k t}$ is availability of power generation technology $k$ in period $t(\mathrm{GW}) ; \eta_{k t}^{ \pm}$is the removal efficiency of sulfur dioxide from power generation technology $k$ in period $t$; $E S_{t}^{ \pm}$is the total allowable emissions of sulfur dioxide during period $t$ (kiloton). $E P_{t}^{ \pm}$is the total allowable emissions of carbon dioxide during period $t$ (kiloton); $Z_{i t}^{ \pm}$is the supply of energy resource $i$ in period $t(\mathrm{PJ}) ; X_{k t}^{ \pm}$is the electricity generation by technology $k$ in period $t(\mathrm{PJ}) ; Y_{k m t}^{ \pm}$is the binary variable for identifying whether or not a capacity expansion action of conversion technology $k$ needs to be undertaken during period $t$.

Based on the interval-parameter credibility constrained programming, the fuzzy resource coefficients in the right-hand side of the regional EPS model can be transformed to their equivalents as follows:

$$
\begin{aligned}
\text { Minimize } f^{ \pm} & =\sum_{i=1}^{3} \sum_{t=1}^{3}\left(P T C_{i t}^{ \pm} \cdot Z_{i t}^{ \pm} \cdot \beta\right)+\sum_{k=1}^{4} \sum_{t=1}^{3}\left(P V_{k t}^{ \pm} \cdot X_{k t}^{ \pm} \cdot \beta\right) \\
& +\sum_{k=1}^{4} \sum_{m=1}^{3} \sum_{t=1}^{3} Y_{k m t}^{ \pm} \cdot\left(F C_{k m t}^{ \pm}+V C_{k t}^{ \pm} \cdot E C P_{k m t} \cdot \beta\right) \\
& +\sum_{k=1}^{4} \sum_{t=1}^{3} \sum_{r=1}^{2}\left(X_{k t}^{ \pm} \cdot C O T_{k t}^{ \pm} \cdot C T_{k t}^{ \pm} \cdot \beta\right)
\end{aligned}
$$

Subject to:

$$
C F_{1 t} \cdot\left[R C_{1}+\sum_{m=1}^{3} \sum_{t^{\prime}=1}^{t} Y_{1 m t}^{ \pm} \cdot E C P_{1 m t}\right] \cdot F E_{1 t}^{ \pm} \leq Z_{1 t}^{ \pm}, \forall t
$$




$$
\begin{aligned}
& C F_{2 t} \cdot\left[R C_{2}+\sum_{m=1}^{3} \sum_{t^{\prime}=1}^{t} Y_{2 m t}^{ \pm} \cdot E C P_{2 m t}\right] \cdot F E_{2 t}^{ \pm} \leq Z_{2 t}^{ \pm}, \forall t \\
& C F_{3 t} \cdot\left[R C_{3}+\sum_{m=1}^{3} \sum_{t^{\prime}=1}^{t} Y_{3 m t}^{ \pm} \cdot E C P_{3 m t}\right] \cdot F E_{3 t}^{ \pm} \leq X_{3 t}^{ \pm}, \forall t \\
& C F_{4 t} \cdot\left[R C_{4}+\sum_{m=1}^{3} \sum_{t^{\prime}=1}^{t} Y_{4 m t}^{ \pm} \cdot E C P_{4 m t}\right] \cdot F E_{4 t}^{ \pm} \leq X_{4 t}^{ \pm}, \forall t \\
& \sum_{k=1}^{4} X_{k t}^{ \pm}+Z_{3 t}^{ \pm} \geq D_{t}+\left(1-2 \lambda^{ \pm}\right)\left(D_{t}-\underline{D}_{t}\right), \forall t \\
& R C_{k}+\sum_{m=1}^{3} \sum_{t^{\prime}=1}^{t} Y_{k m t}^{ \pm} \cdot E C P_{k m t} \leq V_{k t}+\left(1-2 \lambda^{ \pm}\right)\left(V_{k t}-\underline{V}_{k t}\right), \forall t, k=3,4 \\
& \sum_{k=1}^{4} X_{k t}^{ \pm} \cdot \operatorname{COT}_{k t}^{ \pm} \cdot\left(1-\eta_{k t}^{ \pm}\right) \leq E S_{t}^{ \pm}, \forall t \\
& \sum_{k=1}^{4} X_{k t}^{ \pm} \cdot C O P_{k t}^{ \pm} \leq E P_{t}^{ \pm}, \forall t \\
& Y_{k m t}^{ \pm}\{=1 \quad \text { if capacity expansion is undertaken } \\
& =0 \\
& \text { otherwise }
\end{aligned}
$$

\section{Result Analysis and Discussion}

Based on Table 4, the interval credibility is assumed as $[0.6,0.9]$. Two scenarios are analyzed under different policies and practical considerations, where scenarios 1 and 2 represent electric power system without (or with) GHG-emission reduction constraints, respectively.

\subsection{Solution without Considering GHG-emission Reduction}

This case is proposed for generating the pattern of resource production and system development without considering GHGemission reduction. Table 5 shows the obtained results of the energy supply schemes. The coal would always be the largest source among all supplies over three time periods. Its supply would increase significantly from [1917.46, 2261.39] PJ in period 1 to $[2368.54,2716.00] \mathrm{PJ}$ in period 2, and finally reach up to [2971.14, 3075.91] PJ in period 3. The natural gas supply would soar from [1417.13, 1710.29] PJ in period 1 to [1977.53, 2432.24] PJ in period 2, and finally achieve [2580.86,
2673.67] PJ in period 3. The coal supply would increase $21.67 \%$ and natural gas supply would increase $21.85 \%$ in period 2, while in period 3 the coal supply would increase $18.93 \%$ and natural gas supply would increase $45.46 \%$. The reason is that coal-fired power and gas-fired power would be the major power generation technologies without considering GHG-emission reduction due to their advantages of low cost in supply, conversion and capacity expansion compared with others. With the shrinking environmental capacity, the increase rate of natural gas supply would surpass coal supply in period 3 due to the fact that the pollutant generated by coal-fired power is larger than that of gas-fired power. This suggests that gasfired power would always have an advantage over coal-fired power in terms of pollutant emission.

However, development of the coal-fired and natural-gasfired conversion technologies is subjected to the $\mathrm{SO}_{2}$-emission constraint; meanwhile, the electricity generated from these technologies could hardly meet the end-user's demand, making it necessary to develop hydropower and wind power conversion technologies. Figure 2 displays the amount of power generation and facility expansion schemes. The hydropower would grow from [38.5, 42.88] PJ in period 1 to [152.00, 171.00] PJ in period 3 , and the wind power would ascend gradually from $[6.50,7.31] \mathrm{PJ}$ in period 1 to $[31.88,36.56] \mathrm{PJ}$ in period 3 . The hydropower and wind power would have zero contribution to the local pollutant emission inventory, when environmental constraints take effect, it is advantageous to their development, however, their high capital cost would counteract this superiority. Coal-fired power generation would fluctuate over the planning horizon, for example, amount of power generation would amount to [589.99, 646.11] PJ in period 1 and [929.97, 1007.17] PJ in period 3. Gas-fired power generation shows an upward trend, amount of power generation would increase from [578.42, 633.44] PJ in period 1 to [1162.47, 1258.96] in period 3. From period 2, the share of coal-fired power in electricity production is gradually replaced by gas-fired power, it illustrates the constraint of environmental quality has played a important role from then on, it also indicates that the generating efficiency of coal-fired is lower than that of gas-fired power (since the coal supply is larger than that of natural gas supply in periods 2 and 3 ).

Coal-fired power conversion technology would be expanded with $0.1 \mathrm{GW}$ in period $1,0.2 \mathrm{GW}$ in periods 2 and 3 , gas-fired power facilities would be expanded from $0.75 \mathrm{GW}$ in period 2 to $1.35 \mathrm{GW}$ in period 3, hydropower would be expanded with $0.3 \mathrm{GW}$ in period 2 and $0.4 \mathrm{GW}$ in period 3 , there are no expansion for wind power in periods 2 and 3 . Under high environmental demanding, more capacities for electricity generation would select gas-fired power and hydropower for

Table 5. Results of Energy Resources Supply without GHG-emission Reduction

\begin{tabular}{llll}
\hline \multirow{2}{*}{ Energy resources } & \multicolumn{3}{l}{ Energy supply $(\mathrm{PJ})$} \\
\cline { 2 - 4 } & $\mathrm{t}=1$ & $\mathrm{t}=2$ & $\mathrm{t}=3$ \\
\hline Coal & {$[1917.26,2261.39]$} & {$[2368.54,2716.00]$} & {$[2971.14,3075.91]$} \\
Natural gas & {$[1417.13,1710.29]$} & {$[1977.53,2432.24]$} & {$[2580.86,2673.67]$} \\
Imported electricity & {$[670.26,936.59]$} & {$[281.15,543.98]$} & {$[0.00,48.32]$} \\
\hline
\end{tabular}




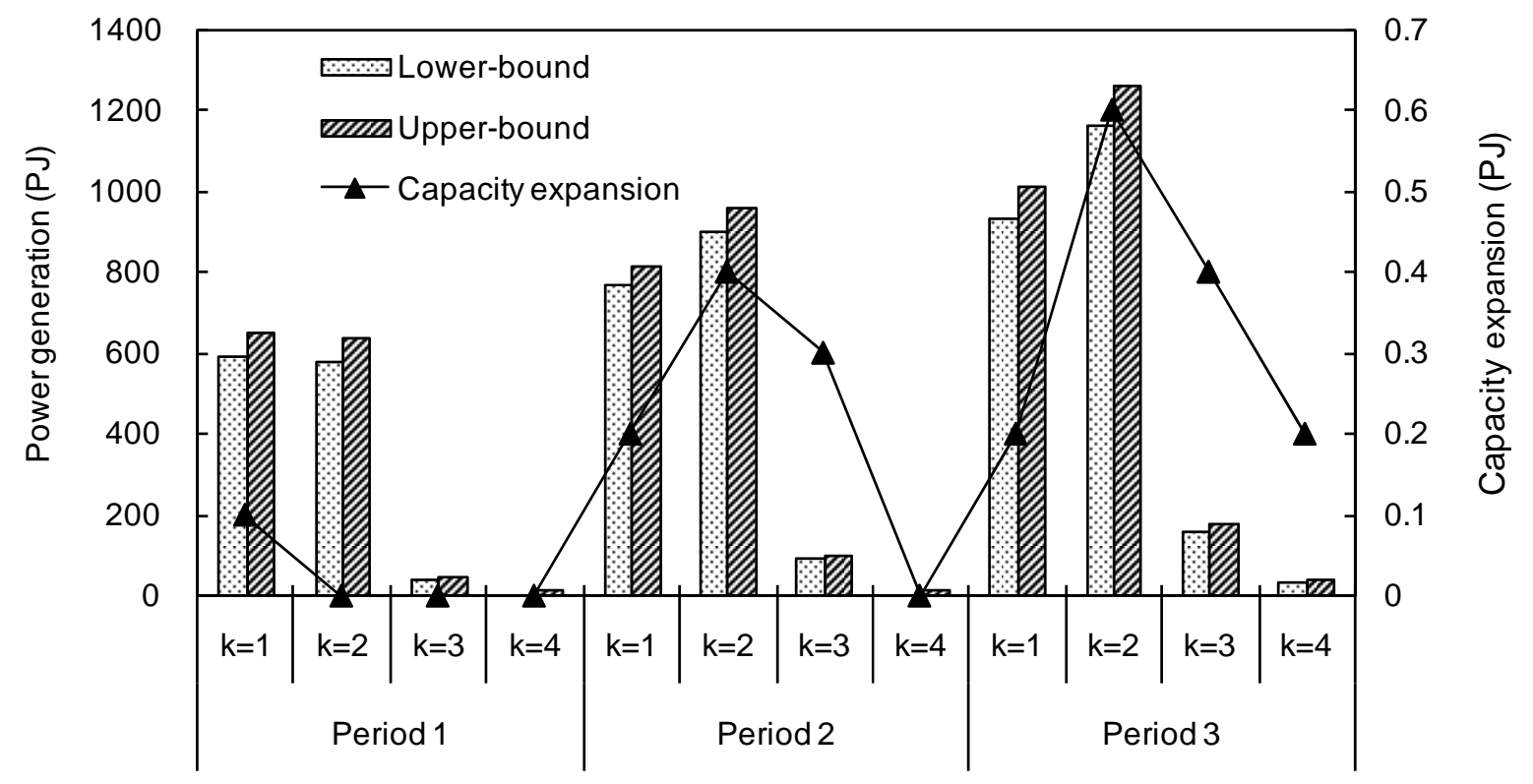

Figure 2. Amount of power generation and facility expansion schemes without GHG-emission reduction.

substitute. The amount of imported electricity would decrease over three periods, i.e. [670.26, 936.59], [281.15, 543.98], $[0.00,48.32] \mathrm{PJ}$, respectively. This would somewhat enhance the stability and security of electric power supply.

\subsection{Solutions with GHG-emission Reduction}

In this scenario, GHG-emission control is considered based on Kyoto Protocol and local emission reduction plans. Table 6 presents the results of energy supply schemes. The capacity-expansion amounts for renewable energy resource would increase in order to reduce GHG emission; meanwhile, it leads to an increased system cost. Coal-fired and gas-fired electricity would no longer be cost-effective option under GHG-emission reduction condition. Compared with the results in scenario 1, the coal supply would drop dramatically from [1886.19, 1917.46] PJ in period 1 to [1631.07, 1828.86] PJ in period 2, and to $[1369.47,1558.49] \mathrm{PJ}$ in period 3. The natural gas supply would decline from [1417.13, 1426.53] PJ in period 1 to $[1230.39,1353.77] \mathrm{PJ}$ in period 3 . The coal supply would decrease $13.53 \%$ in period 2 and $16.04 \%$ in period 3, and natural gas supply would decrease $15.76 \%$ in period 3 . In general, the supply of coal and natural gas show a downtrend, the fall of coal supply is larger than that of natural gas supply, especially in period 3 . The main reason is attributed to the fact that the fossil fuel would generate a large amount of GHG and pollutant emissions in the conversion process. Subjected to the GHG-emission and environmental constraints, coal-fired power and gas-fired power would increasingly displaced by hydropower and wind power. However, within the limit of environmental constraint, the major power generation technology would still be coal-fired power and gas-fired power due to their low capital advantages.

Figure 3 shows the amount of power generation and facility expansion schemes under GHG-emission reduction constraint. Coal-fired power generation would be [538.91, 589.99] $\mathrm{PJ}$ in period 1 and [486.89, 589.95] $\mathrm{PJ}$ in period 2 finally $[427.96,528.30] \mathrm{PJ}$ in period 3 , gas-fired power generation would fluctuate from [528.34, 578.42] $\mathrm{PJ}$ in period 1 to $[534.95,660.38] \mathrm{PJ}$ in period 3. Gas-fired power would have been the major electricity supply since period 2. Its amount of power generation is basically remained unchanged in the period 3. The reason is that environmental carrying capacity has reached the maximum limit since period 2 . In order to meet the rising electric demand, more electricity would turn to hydropower and wind power as well as imported electricity. The hydropower would grow from [84.70, 94.33] $\mathrm{PJ}$ in period 1 to $[165.38,185.06] \mathrm{PJ}$ in period 2, and to $[248.00,279.00] \mathrm{PJ}$ in period 3 . The wind power would soar from $[32.5,36.56] \mathrm{PJ}$ in period 1 to $[71.23,80.85] \mathrm{PJ}$ in period 2, and to $[121.13,138.94] \mathrm{PJ}$ in period 3. Amount of hydropower would increase $95.25 \%$ in period 2 and $49.96 \%$ in period 3. Amount of wind power would increase $119.17 \%$

Table 6. Results of Energy Resources Supply with GHG-emission Reduction

\begin{tabular}{llll}
\hline \multirow{2}{*}{ Energy resources } & \multicolumn{3}{l}{ Energy supply $(\mathrm{PJ})$} \\
\cline { 2 - 4 } & $\mathrm{t}=1$ & $\mathrm{t}=2$ & $\mathrm{t}=3$ \\
\hline Coal & {$[1886.19,1917.46]$} & {$[1631.07,1828.86]$} & {$[1369.47,1558.49]$} \\
Natural gas & {$[1417.13,1426.53]$} & {$[1460.66,1526.94]$} & {$[1230.39,1353.77]$} \\
Imported electricity & {$[801.86,864.39]$} & {$[779.38,824.39]$} & {$[892.20,919.15]$} \\
\hline
\end{tabular}




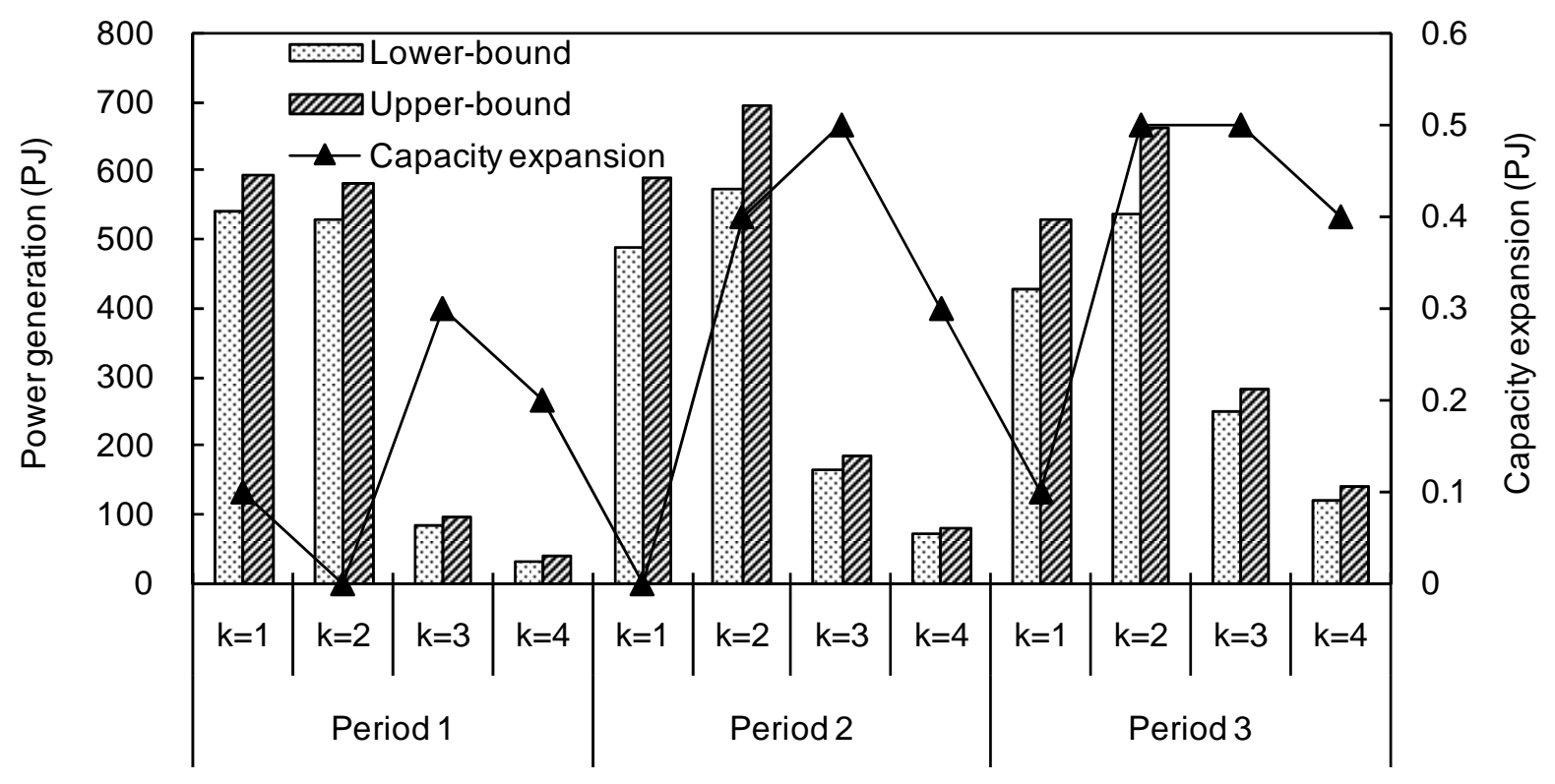

Figure 3. Amount of power generation and facility expansion schemes under GHG-emission reduction.

in period 2 and $70.05 \%$ in period 3 . The development speed would drop in period 3 . The reason is that the available amounts of renewable energy resources (hydropower and wind power) are limited. The facilities expanded capacity is $0.2,0.9,1.3$, and $0.9 \mathrm{GW}$ for coal-fired power, gas-fired power, hydropower and wind power, respectively. The amount of imported electricity would generally increase over the three planning periods, i.e. [801.86, 864.39], [779.38, 824.39], and [892.20, 919.15] PJ, respectively.

\subsection{Comparative Analysis between Two Scenarios}

The power structure has changed dramatically under different scenarios, especially in the power supply ratio of coal-fired and gas-fired power. As shown in Figures 4 and 5, without considering GHG-emission reduction, the main power generation technologies are coal-fired and gas-fired power and the power supply ratio are increasing over the periods; while subjected to GHG-emission reduction constraint, the four power generation technologies show a tendency of balanced development. Figure 6 shows the amount of capacity expansion under the two scenarios. The renewable energy generation technologies do not proliferate fast, and slower than coal-fired and gas-fired power technologies in scenario 1.

\section{Conclusions}

In this study, an interval-parameter credibility constrained programming was developed to support regional electric power system planning under uncertainty. The developed method coupled interval parameter programming and credibility constrained programming into a general framework, and could reflect uncertainties expressed as both discrete intervals and fuzzy sets. The model also allowed satisfaction of system constraints at
Power structure in period 1

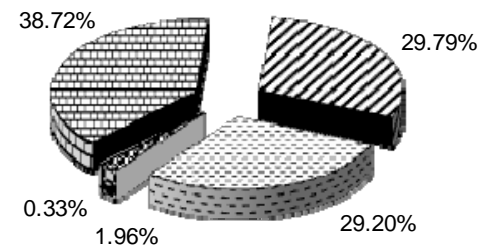

Power structure in period 2

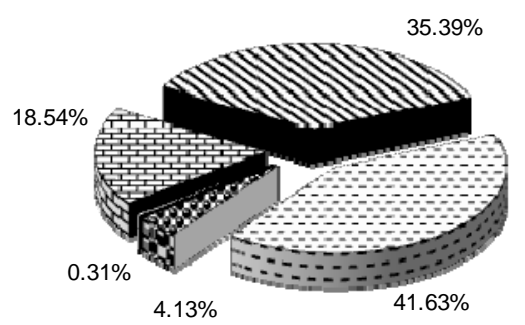

Power structure in period 3

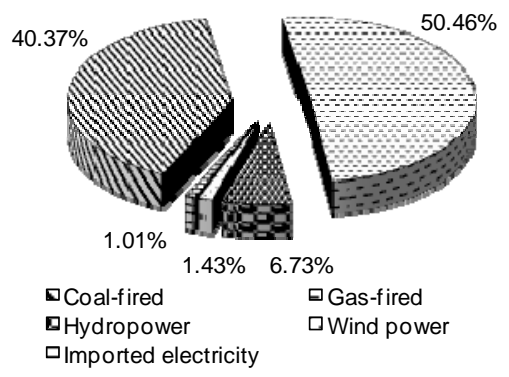

Figure 4. Power structure in three periods under scenario 1. 
Power structure in period 1

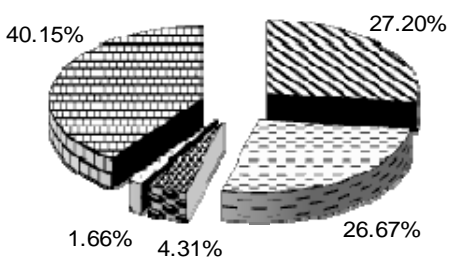

Power structure in period 2
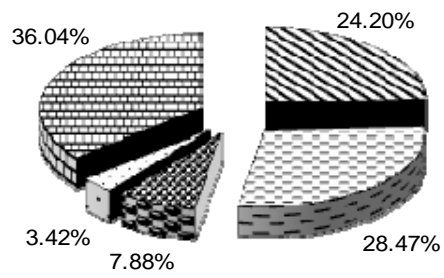

Power structure in period 3

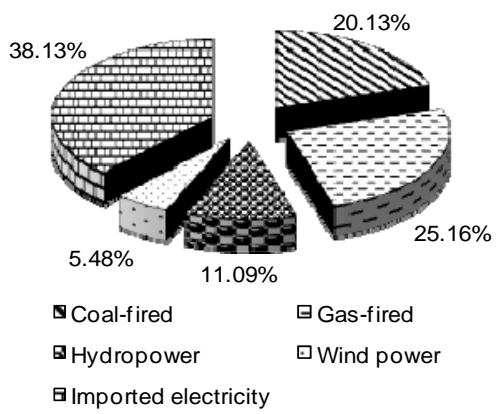

Figure 5. Power structure in three periods under scenario 2.

specified confidence levels. Given the interval credibility levels for constraints, the ICCP model can be transformed to its equivalent two sub-models. The resulting solutions can provide stable intervals for the objective function and decision variables with different levels of constraint-violation risks. The developed method was applied to a regional electric power system planning case. 11 semantic scales were established to present the credibility levels of decision makers. Issues concerning energy resources allocation, capacity expansion of generating equipment as well as GHG-emission reduction were addressed. The results suggested that the proposed hybrid method was applicable to practical problems associated with highly complex and uncertain information. The results also implied that the ICCP technique could be extended to other engineering decision-making problems, such as water resource management and air pollution control planning (Liu et al., 2007a, b, 2008).

The proposed model could help regional electric power system mangers to obtain desired management schemes under various economic and risk considerations. However, there are still a lot of limitations of the proposed method. Compared with other inexact optimization methods, the model would encounter difficulties when the model's right-hand-side coeffi-
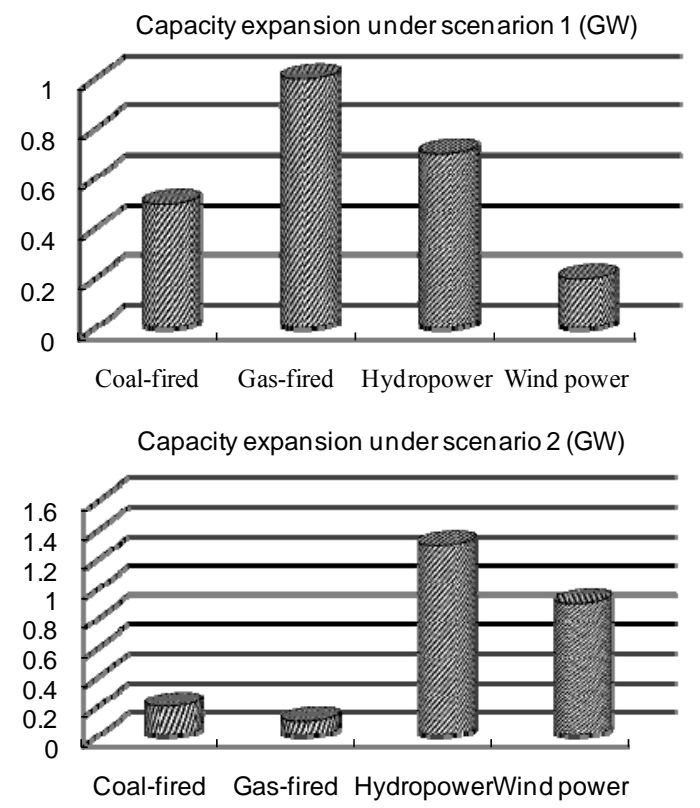

Figure 6. Capacity expansion schemes of various power generation technologies under two scenarios.

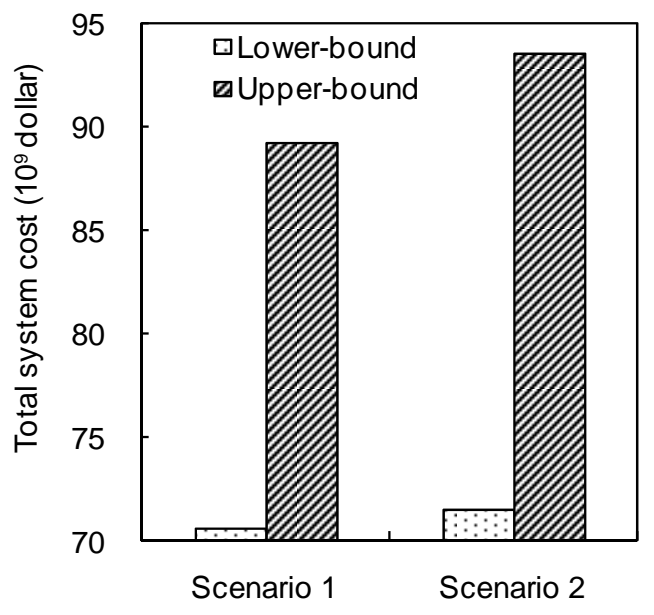

Figure 7. The total system cost under two cases.

cients are highly uncertain; the random character of energy system parameters and theirs relationship can be hardly reflect by the ICCP model (Cai et al., 2009a, b; Fan and Huang, 2012; Li et al. 2009; Li et al., 2011; Fan et al., 2017; Wang et al., 2018). Therefore, further studies are desired to mitigate these limitations.

Acknowledgement. This research was supported by the National Key Research and Development Plan (2016YFC0502800, 2016YFA0601502), the Natural Sciences Foundation (61471171, 51520105013, 51679087), the 111 Program (B14008), the Environmental Protection Public Welfare Scientific Research Project (201509010) and the Natural Science and Engineering Research Council of Canada. The authors are extremely grateful to the editor and the anonymous reviewers for their insightful comments and suggestions. 


\section{References}

An, C.J., McBean, E., Huang, G.H., Yao, Y., Zhang, P., Chen, X.J., and Li, Y.P. (2016). Multi-soil-layering systems for wastewater treatment in small and remote communities. J. Environ. Inf., 27(2), 131-144. https://doi.org/10.3808/jei.201500328

Atkins, M.J., Morrison, A.S., and Walmsley, M.R.W. (2010). Carbon Emissions Pinch Analysis (CEPA) for emissions reduction in the New Zealand electricity sector. Appl. Energy, 87(3), 982-987. http://dx.doi.org/10.1016/j.apenergy.2009.09.002

Bishop, J.D.K., Amaratunga, G.A.J., and Rodriguez, C. (2010). Linking energy policy, electricity generation and transmission using strong sustainability and co-optimization. Electric Power Syst. Res., 80(6), 633-641. http://dx.doi.org/10.1016/j.epsr.2009.10.014

Cai, Y.P., Huang, G.H., Yang, Z.F., Lin, Q.G., Bass, B., and Tan, Q. (2008). Development of an optimization model for energy systems planning in the Region of Waterloo. Int. J. Energy Res., 32(11), 988-1005. http://dx.doi.org/10.1002/er.1407

Cai, Y.P., Huang, G.H., Yang, Z.F., Lin, Q.G., Bass, B., and Tan, Q. (2008). Development of an optimization model for energy systems planning in the region of Waterloo. Int. J. Energ. Res., 32(11), 988-1005. https://doi.org/10.1002/er.1407

Cai, Y.P., Huang, G.H., Yang, Z.F., Lin, Q.G., and Tan, Q. (2009a). Community-scale renewable energy systems planning under uncertainty-An interval chance-constrained programming approach. Renew. Sustainable Energy Rev., 13(4), 721-735. http://dx. doi.org/10.1016/j.rser.2008.01.008

Cai, Y.P., Huang, G.H., Yang, Z.F., and Tan, Q. (2009b). Identification of optimal strategies for energy management systems planning under multiple uncertainties. Appl. Energ., 86(4), 480-495. https:// doi.org/10.1016/j.apenergy.2008.09.025

Cao, M.F., Huang, G.H., and Lin, Q.G. (2010). Integer programming with random-boundary interval for planning municipal power systems. Appl. Energy, 87(8), 2506-2516. http://dx.doi.org/10.10 16/j.apenergy.2010.03.005

Chanas, S. and Zielinski, P. (2000). On the equivalence of two optimization methods for fuzzy linear programming problems. Eur. J. Oper. Res., 121(1), 56-63. http://dx.doi.org/10.1016/S0377-2217 (99)00011-9

Cheng, S., Chan, C.W., and Huang, G.H. (2002). Using multiple criteria decision analysis for supporting decisions of solid waste management. J. Environ. Sci. Heal. A, 37(6), 975-990. https://doi. org/10.1081/ESE-120004517

Cranston, G.R., and Hammond, G.P. (2010). North and south: Regional footprints on the transition pathway towards a low carbon, global economy. Appl. Energy, 87(9), 2945-2951. http://dx. doi.org/10.1016/j.apenergy.2009.08.015

Darby-Dowman, K., Barker, S., Audsley, E., and Parsons, D. (2000). A two-stage stochastic programming with recourse model for determining robust planting plans in horticulture. J. Oper. Res. Soc., 51, 83-98. http://dx.doi.org/10.1057/palgrave.jors.2600858

Dentcheva, D., and Römisch, W. (1998). Optimal power generation under uncertainty via stochastic programming, in K. Marti and P. Kall (Eds.), Stochastic Programming Methods and Technical Applications, Springer-Verlag Berlin Heidelberg, vol. 458, pp. 22-56. http://dx.doi.org/10.1007/978-3-642-45767-8 2

Dong, C., Huang, G.H., Cai, Y.P., and Xu, Y. (2011). An intervalparameter minimax regret programming approach for power management systems planning under uncertainty. Appl. Energy, 88(8), 2835-2845. http://dx.doi.org/10.1016/j.apenergy.20 11.01.056

Dubois, D., and Prade, H. (1988). Possibility Theory: An Approach to Computerized Processing of Uncertainty, Spring-Verlag US. http://dx.doi.org/10.1007/978-1-4684-5287-7

Fan, Y.R. and Huang, G.H. (2012). A robust two-step method for solving interval linear programming problems within an environmental management context. J. Environ. Inf., 19(1), 1-9. https://doi. org/10.3808/jei.201200203

Fan, Y.R., Huang, G. H., Baetz, B. W., Li, Y. P., and Huang, K. (2017). Development of a Copula-based particle filter (CopPF) approach for hydrologic data assimilation under consideration of parameter interdependence. Water Resour. Res., 53, 4850-4875, doi:10.1002/2016WR020144

Gong, W., Duan, Q.Y., Li, J.D., Wang, C., Di, Z.H., Ye, A.Z., Miao, Y.J., and Dai, Y.J. (2016). An intercomparison of sampling methods for uncertainty quantification of environmental dynamic models. J. Environ. Inf., 28(1), 11-24. https://doi.org/10.3808/jei. 201500310

Grosfeld-Nir, A., and Tishler, A. (1993). A stochastic model for the measurement of electricity outage costs. Energy, 14(2), 157-174. http://dx.doi.org/10.5547/issn0195-6574-ej-vol14-no2-8

Guo, L., Li, Y.P., Huang, G.H., Wang, X.W., and Dai, C. (2012). Development of an interval-based evacuation management model in response to nuclear-power plant accident. J. Environ. Inf., 20(2), 58-66. https://doi.org/10.3808/jei.201200220

Huang, G.H., Baetz, B.W., and Patry, G.G. (1992). A grey linear programming approach for municipal solid waste management planning under uncertainty. Civ. Eng. Syst., 9(4), 319-335. http://dx. doi.org/10.1080/02630259208970657

Huang, G.H., Baetz, B.W., and Patry, G.G. (1993). A grey fuzzy linear programming approach for municipal solid waste management planning under uncertainty. Civ. Eng. Syst., 10(2), 123-146. http://dx.doi.org/10.1080/02630259308970119

Huang, G.H., and Chang, N.B. (2003). The perspectives of environmental informatics and systems analysis. J. Environ. Inf., 1(1), 1-7. http://dx.doi.org/10.3808/jei.200300001

Huang, X. (2006). Credibility-based chance-constrained integer programming models for capital budgeting with fuzzy parameters. Inf. Sci., 176(18), 2698-712. http://dx.doi.org/10.1016/j.ins.2005.11.012

Huang, G.H., Cohen, S.J., Yin, Y.Y., and Bass, B. (1996). Incorporation of inexact dynamic optimization with fuzzy relation analysis for integrated climate change impact study. J. Environ. Manage., 48(1), 45-68. https://doi.org/10.1006/jema.1996.0065

Huang, G. H., and Cao, M. F. (2011). Analysis of solution methods for interval linear programming. J. Environ. Inf., 17(2) 54-64. https://doi.org/10.3808/jei.201100187

Li, W., Huang, G.H., Dong, C., and Liu, Y. (2013). An inexact fuzzy programming approach for power coal blending. J. Environ. Inf., 21(2), 112-118. http://dx.doi.org/10.3808/jei.201300238

Li, Y.F., Huang, G.H., Li, Y.P., Xu ,Y., and Chen, W.T. (2010). Regional-scale electric power system planning under uncertainty A multistage interval-stochastic integer linear programming approach. Energ. Policy, 38(1), 475-490. http://dx.doi.org/10.1016/j. enpol.2009.09.038

Li, Y.P., and Huang, G.H. (2009). Fuzzy-stochastic-based violation analysis method for planning water resources management systems with uncertain information. Inf. Sci., 179(24), 4261-4276. https:// doi.org/10.1016/j.ins.2009.09.001

Li, Y.P., Huang, G.H., and Chen, X.Q. (2011). Planning regional energy system in association with greenhouse gas mitigation under uncertainty. Appl. Energ., 88(3), 599-611. https://doi.org/10.1016/j. apenergy.2010.07.037

Li, Y.P., Huang, G.H., and Nie, S.L. (2010). Planning water resources management systems using a fuzzy-boundary interval-stochastic programming method. Adv. Water Resour., 33(9), 1105-1117. https://doi.org/10.1016/j.advwatres.2010.06.015

Li, Y.P., Huang, G.H., and Nie, S.L. (2007). Mixed interval-fuzzy two-stage integer programming and its application to flood-diversion planning. Eng. Optimiz., 39(2), 163-183. https://doi.org/10. 1080/03052150601044831 
Li, Y.P., Huang, G.H., Huang, Y.F., and Zhou, H.D. (2009). A multistage fuzzy-stochastic programming model for supporting sustainable water-resources allocation and management. Environ. Model. Software, 24(7), 786-797. https://doi.org/10. 1016/j.envsoft. 2008.11.008

Lin, Q.G., and Huang, G.H. (2008). IPEM: An interval-parameter energy systems planning model. Energy Source Part A Recovery Util. Environ. Effects, 30(14-15), 1382-1399. http://dx.doi.org/10. 1080/15567030801929043

Lin, Q.G., and Huang, G.H. (2010). An inexact two-stage stochastic energy system planning model for managing greenhouse gas emission at a municipal level. Energy, 35(5), 2270-2280. http://dx. doi.org/10.1016/j.energy.2010.01.042

Lin, Y.P., and Chen, B.S. (2016). Natural resource management for nonlinear stochastic biotic-abiotic ecosystems: robust reference tracking control strategy using limited set of controllers. J. Environ. Inf., 27(1), 14-30. https://doi.org/10.3808/jei.201400286

Liu, B., and Liu, Y.K. (2002). Expected value of fuzzy variable and fuzzy expected value models. IEEE Trans. Fuzzy Syst., 10(4), 445-450. http://dx.doi.org/10.1109/TFUZZ.2002.800692

Liu, L., Huang, G.H., Fuller, G.A., Chakma, A., and Guo, H.C. (2000). A dynamic optimization approach for nonrenewable energy resources management under uncertainty. J. Pet. Sci. Eng., 26(1-4), 301-309. http://dx.doi.org/10.1016/S0920-4105(00)00044-9

Liu, Y., Qin, X., Guo, H., Zhou, F., Wang, J., Lv, X., and Mao, G. (2007a). ICCLP: An inexact chance-constrained linear programming model for land-use management of lake areas in urban fringes. Environ. Manage., 40(6), 966-980. http://dx.doi.org/10. 1007/s00267-007-9013-2

Liu, Y., Lv, X., Qin, X., Guo, H., Yu, Y., Wang, J., and Mao, G. (2007b). An integrated GIS-based analysis system for land-use management of lake areas in urban fringe. Landscape Urban Plann., 82(4), 233-246. http://dx.doi.org/10.1016/j.landurbplan.2007. 02.012

Liu, Z.F., Huang, G.H., Liao, R.F., and He, L. (2009). DIPIP: Dual interval probabilistic integer programming for solid waste management. J. Environ. Inf., 14(1), 66-73. http://dx.doi.org/10.3808/ jei.200900154

Lu, H.W., Huang, G.H., Zeng, G.M., Maqsood, I., and He, L. (2008). An inexact two-stage fuzzy-stochastic programming model for water resources management. Water Resour. Manag., 22(8), 9911016. https://doi.org/10.1007/s11269-007-9206-8

Mariano, J., Arenas, M., Bilbao, A., and Victoria Rodríguez, M. (2007). Linear programming with fuzzy parameters: An interactive method resolution. Eur. J. Oper. Res., 177(3), 1599-1609. http://dx. doi.org/10.1016/j.ejor.2005.10.002

Martín-Fernández, L., Ruiz, D.P., Torija, A.J., and Míguez, J. (2016). A Bayesian method for model selection in environmental noise prediction. J. Environ. Inf., 27(1), 31-42. https://doi.org/10.3808/ jei.201500295

Muela, E., Schweickardt, G., and Garcés, F. (2007). Fuzzy possibilistic model for medium-term power generation planning with environmental criteria. Energy Policy, 35(11), 5643-5655. http:// dx.doi.org/10.1016/j.enpol.2007.05.020

Pousinho, H.M.I., Mendes, V.M.F., and Catalão, J.P.S. (2011). A risk-averse optimization model for trading wind energy in a market environment under uncertainty. Energy, 36(8), 4935-4942. http:// dx.doi.org/10.1016/j.energy.2011.05.037
Qin, X.S. (2012). Assessing environmental risks through fuzzy parameterized probabilistic analysis. Stochastic Environ. Res. Risk Assess., 26(1), 43-58. http://dx.doi.org/10.1007/s00477-010-04 54-4

Rong, A., and Lahdelma, R. (2008). Fuzzy chance constrained linear programming model for optimizing the scrap charge in steel production. Eur. J. Oper. Res., 186(3), 953-964. http://dx.doi.org/ 10.1016/j.ejor.2007.02.017

Shimazaki, Y., Akisawa, A., and Kashiwagi, T. (2000). A model analysis of clean development mechanisms to reduce both $\mathrm{CO}_{2}$ and $\mathrm{SO}_{2}$ emissions between Japan and China. Appl. Energy, 66(4), 311-324. http://dx.doi.org/10.1016/S0306-2619(00)00020-9

Siitonen, S., Tuomaala, M., Suominen, M., and Ahtila, P. (2010). Implications of process energy efficiency improvements for primary energy consumption and $\mathrm{CO}_{2}$ emissions at the national level. Appl. Energy, 87(9), 2928-2937. http://dx.doi.org/10.1016/j.apenergy.2009. 09.024

Svensson, E., Strömberg, A.B., and Patriksson, M. (2011). A model for optimization of process integration investment under uncertainty. Energy, 36(5), 2733-2746. http://dx.doi.org/10.1016/j.energy. 2011.02.013

Tong, L.I., Saminathan, R., and Chang, C.W. (2016). Uncertainty assessment of non-normal emission estimates using nonparametric bootstrap confidence intervals. J. Environ. Inf., 28(1), 61-70. https://doi.org/10.3808/jei.201500322

Wang, L., Huang, G.H., Wang, X.Q., and Zhu, H. (2018). Risk-based electric power system planning for climate change mitigation through multi-stage joint-probabilistic left-hand-side chance-constrained fractional programming: A Canadian case study. Renew. Sustainable Energy Rev., 82, 1056-1067. https://doi.org/10.1016/j. rser.2017.09.098

Wang, X., Huang, G.H., Liu, Z., and Dai, C. (2012). Hybrid inexact optimization approach with data envelopment analysis for environment management and planning in the City of Beijing, China. Environ. Eng. Sci., 29(5), 313-327. http://dx.doi.org/10.1089/ees. 2010.0424

Xi, B.D., Qin, X.S., Su, X.K., Jiang, Y.H., and Wei, Z.M. (2008). Characterizing effects of uncertainties in MSW composting process through a coupled fuzzy vertex and factorial-analysis approach. Waste Manage., 28(9), 1609-1623. http://dx.doi.org/10. 1016/j.wasman.2007.06.027

Xie, Y.L., Li. Y.P., Huang, G.H., and Li, Y.F. (2010). An interval fixed-mix stochastic programming method for greenhouse gas mitigation in energy systems under uncertainty. Energy, 35(12), 4627-4644. http://dx.doi.org/10.1016/j.energy.2010.09.045

$\mathrm{Xu}$, Y., Huang, G.H., and $\mathrm{Xu}$, T.Y. (2012). Inexact management modeling for urban water supply systems. J. Environ. Inf., 20(1), 34-43. http://dx.doi.org/10.3808/jei.201200218

Yin, Y.Y., Huang, G.H., and Hipel, K.W. (1999). Fuzzy relation analysis for multicriteria water resources management. J. Water Res. Pl.-ASCE, 125(1), 41-47. https://doi.org/10.1061/(ASCE) 07339496(1999)125:1(41)

Zadeh, L.A. (1978). Fuzzy sets as a basis for a theory of possibility. Fuzzy Sets Syst., 1(1), 3-28. http://dx.doi.org/10.1016/0165-0114 (78) $90029-5$

Zhang, Y.M., and Huang, G.H. (2011). Inexact credibility constrained programming for environmental system management. Resour. Conserv. Recycling, 55(4), 441-447. http://dx.doi.org/10.1016/j.res conrec.2010.11.007 